\title{
A narradora descolonial: uma leitura de The Distant Marvels, de Chantel Acevedo
}

\author{
Priscilla da Silva Figueiredo' (iD) 0000-0001-8765-6317 \\ 'Universidade do Estado do Rio de Janeiro, Centro de Educação e Humanidades, \\ Programa de Pós-Graduação em Letras, Rio de Janeiro, RJ, Brasil. 20550-900 - \\ secretaria_pgletras@yahoo.com.br
}

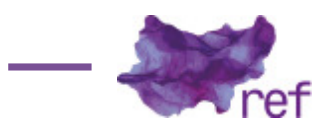

Resumo: Em "O narrador. Reflexões sobre a obra de Nicolai Leskov" (1987a), Walter Benjamin entende que a arte de narrar está em vias de extinção uma vez que o narrador, aquele que reúne em si mesmo o conhecimento do camponês sedentário e do marinheiro comerciante, parece não estar mais entre nós a partir da modernidade. Entretanto, se seguirmos a argumentação de Maria Lugones em "Rumo a um feminismo descolonial" (2014a), que coloca o [des]colonial dentro de uma categoria de não moderno, poderemos considerar que a presença do narrador é perene e se manifesta muitas vezes exatamente no romance, forma literária que Benjamin (1987a) aponta como um indicativo da evolução que vai culminar na morte da narrativa. Em The Distant Marvels (2015), a autora cubana-americana Chantel Acevedo constrói uma protagonista que é a representação literária de um narrador que reúne em si as características benjaminianas e que é, assim, capaz de transmitir experiência. A proposta do presente trabalho é verificar como uma leitura deste romance a partir do viés da descolonialidade pode contribuir para o debate acerca da potência que a intervenção estética feminista tem de contribuir para a construção de novas epistemologias.

Palavras-chave: Descolonialidade; O narrador; Intervenção de estética feminista

The Decolonial Narrator: A Reading of The Distant Marvels, by Chantel Acevedo Abstract: In "The Storyteller: Reflections on the Work of Nicolai Lescov" (1987a), Walter Benjamin understands that the art of storytelling is about to become extinct once the storyteller, that one who gets his/her full corporeality when reunites the knowledge of the resident master craftsman and the traveling journeyman, seems to be no longer among us. However, when taking into consideration Maria Lugones (2014a) understandings of the decolonial, that it inhabits a non modern space, it is possible to admit the presence of the Benjaminian narrator, sometimes in the novel, genre that the he understood as a symptom of a process whose end is the death of the storytelling. In the novel The Distant Marvels (2015), the CubanAmerican author Chantel Acevedo creates a protagonist who is a literary representation of a narrator that incorporates the Benjaminian characteristics and, therefore, is competent in transmitting experience. The following article intends to verify how a decolonial reading of the aforementioned novel may contribute to the work of developing new epistemologies.

Keywords: Decoloniality; The Storyteller; Feminist aesthetics

Que foi feito de tudo isso? Quem encontra ainda pessoas que saibam contar histórias como elas devem ser contadas? Que moribundos dizem hoje palavras tão duráveis que possam ser transmitidas como um anel, de geração em geração? Walter Benjamin - Experiência e pobreza

Em março de 1936, Walter BENJAMIN escreve seu ensaio "O narrador. Reflexões sobre a obra de Nicolai Leskov", no qual discute como a arte de narrar começa a entrar em processo de extinção a partir da modernidade porque, segundo ele, a experiência (erfahrung) estaria se tornando incomunicável. A guerra de trincheiras, a inflação, entre outros fenômenos presentes até hoje, teriam sido alguns dos responsáveis pelo empobrecimento da experiência, que é transmitida de pessoa a pessoa e que "é a fonte a que recorrem todos os narradores" (BENJAMIN, 1987a [1936], p. 200). Sem a transmissão da experiência, sentencia Benjamin, extinguiriam-se os narradores. Se, 
contudo, levarmos em consideração a argumentação de Maria Lugones (2014a) em seu artigo "Rumo a um feminismo descolonial" e entendermos o descolonial dentro de uma categoria de não moderno, poderemos considerar que a presença do narrador é perene e se manifesta muitas vezes no romance, forma literária que Benjamin aponta como um "indício da evolução que vai culminar na morte da narrativa" (BENJAMIN, 1987a, p. 201). Em The Distant Marvels (2015), por exemplo, a autora cubana-americana Chantel Acevedo constrói uma protagonista/narradora que pode ser considerada uma representação literária daquele narrador benjaminiano, tornandose, assim, capaz de transmitir a erfahrung. A proposta do presente artigo é, portanto, fazer uma análise do romance supracitado e investigar como a descolonialidade pode se tornar uma chave de leitura que contribua para o debate acerca da potência que a intervenção estética feminista tem de contribuir para a construção de novas epistemologias.

Apesar de amplamente abraçado pelas diversas áreas das ciências sociais e humanas, que o utilizam como um espelho da modernidade e suas contradições, é importante lembrarmos que, desde o título, Walter Benjamin deixa claro ao seu leitor que seu ensaio se trata, principalmente, apesar de não exclusivamente, de uma crítica literária cujo principal objetivo é apresentar o autor russo Nicolai Leskov como um exemplo de narrador para poder, a partir dele, diferenciá-lo do romancista. Dentre as diversas características que separam o narrador do romancista, uma parece se destacar para Benjamin: enquanto o narrador retirava a inspiração para suas histórias do conhecimento dos costumes e tradições, se baseando, desta forma, na erfahrung, que poderia ser definida como a experiência ligada à coletividade, o romancista privilegiava a erlebniz, a experiência individual, tão cara ao romance burguês, o qual foi seu contemporâneo. Em suas próprias palavras,

o narrador retira da experiência o que ele conta: sua própria experiência ou relatada pelos outros. E incorpora as coisas narradas à experiência dos seus ouvintes. O romancista segregase. A origem do romance é o indivíduo isolado, que não pode mais falar exemplarmente sobre suas preocupações mais importantes e que não recebe conselhos nem sabe dá-los (BENJAMIN, 1987a, p. 201).

Estando as ações da experiência cada vez mais escassas na modernidade, de acordo com o autor, seria inevitável que a arte narrativa e o narrador desaparecessem definitivamente. "Descrever um Leskov como narrador não significa trazê-lo para perto de nós, e sim, pelo contrário, aumentar a distância que nos separa dele", afirma Benjamin (1987a, p. 197).

Seguindo em seu ensaio, Benjamin identifica que o narrador e a arte de narrar estariam ligados a dois tipos arcaicos que exemplificariam grupos de características próprias, sendo um deles o camponês sedentário e o outro, o marinheiro comerciante. Durante a ldade Média, esses dois tipos foram aperfeiçoados nos artífices, cujas vidas associavam o saber das terras distantes e as histórias e tradições de sua localidade, uma vez que "o mestre sedentário e os aprendizes migrantes trabalhavam juntos na mesma oficina; cada mestre tinha sido um aprendiz ambulante antes de se fixar em sua pátria ou no estrangeiro" (BENJAMIN, 1987a, p. 198). Benjamin conclui que se o romance ameaça a experiência de cunho coletivo, a informação seria a responsável por ameaçar a autoridade do saber que vem de longe (seja o longe espacial ou temporal), pois "a informação aspira a uma verificação imediata" (BENJAMIN, 1987a, p. 202).

Walter Benjamin se debruça sobre outras características do narrador e decifra os motivos pelos quais elas estão em declínio na modernidade que se apresenta diante dele. Dentre eles, dois nos interessam para o presente artigo: em primeiro lugar, a importância da morte para a narrativa. Ele afirma que "é no momento da morte que o saber e a sabedoria do homem e, sobretudo sua existência vivida - e é dessa substância que são feitas as histórias -, assumem pela primeira vez uma forma transmissível" (1987a, p. 207). E, em segundo lugar, o fato de que a narração não se limita à voz (ou à escrita); ela envolve a alma, o olho e a mão. Segundo Benjamin (1987a), na verdadeira narração, "a antiga coordenação da alma, do olhar e da mão (... é é típica do artesão, e é ela que encontramos sempre, onde quer que a arte de narrar seja praticada" (p. 221).

Se Benjamin estava correto e a arte de narrar e o narrador não estão presentes na modernidade, por que conseguimos localizá-los mesmo em alguns romances, como, por exemplo, acontece em The Distant Marvels, da escritora cubano-estadunidense Chantel Acevedo? A resposta que encontramos está na possibilidade de adotarmos uma postura similar à de Maria Lugones em seu artigo "Rumo a um feminismo descolonial" e considerarmos esta figura como sendo característica não do pré-moderno, mas do não moderno, seguindo Juan APARICIO e Mario BLASER (2008). De acordo com Aparicio e Blaser (2008), o desafio seria, portanto, recuperar um entendimento sobre a modernidade e sua especificidade de maneira que reconheçamos que existem outros mundos de vida que não estejam encaixados entre modernos ou tradicionais, ou seja, os mundos não modernos. Assim, o narrador poderia estar presente, por exemplo, "em organizações sociais nas quais as pessoas têm resistido à modernidade capitalista e estão em tensão com essa lógica", ou seja, talvez o narrador benjaminiano esteja presente nesse espaço onde a modernidade não está presente. 
O artigo supracitado de Maria Lugones é uma ferramenta importante para a possibilidade de uma leitura do romance de Acevedo como uma obra descolonial. É neste artigo em que a filósofa argentina desenvolve o conceito de colonialidade de gênero. Segundo ela, a partir da colonização das Américas e do Caribe se estabelece uma dicotomia hierárquica entre o humano e o não humano. Tal distinção dicotômica veio acompanhada de outras, incluindo a diferença entre homens e mulheres. Assim, de acordo com Lugones, após a colonização, só os tais civilizados seriam homens ou mulheres. Os colonizados seriam tidos como espécies não humanas, animais, incontrolavelmente sexuais e selvagens e as pessoas colonizadas teriam se tornado macho e fêmea a partir de uma lógica negativa. Em suas palavras, "[m]achos tornaram-se não-humanos por não-homens, e fêmeas colonizadas tornaram-se não-humanas por não-mulheres" (LUGONES, 2014a, p. 937).

Lugones prossegue apontando como a missão civilizatória colonial permitiu um acesso com requintes de brutalidade inimaginável aos corpos, memórias, noções de si, relações subjetivas e com a terra, entre outras coisas, das pessoas. Além de todo tipo de perversidade sexual, "a normatividade que conectava gênero e civilização concentrou-se no apagamento das práticas comunitárias ecológicas, saberes de cultivo, de tecelagem, do cosmos, e não somente na mudança e no controle das práticas reprodutivas e sexuais" (LUGONES, 2014a, p. 938). Assim, segundo Lugones, o sistema moderno colonial de gênero teria sido responsável pela desumanização constitutiva da colonialidade do ser. Seguindo teóricos como Aníbal Quijano e Nelson MaldonadoTorres, Maria Lugones estende os conceitos de colonialidade do poder (Quijano) e colonialidade do ser (Maldonado-Torres) e utiliza a ideia de colonialidade não apenas para denominar uma classificação de povos em relação a poder e gênero, mas também ao "processo de redução ativa das pessoas, [à] desumanização que as torna aptas para a classificação, o processo de sujeitificação e a investida de tornar o colonizado/a menos que seres humanos" (LUGONES, 2014a, p. 938). Apenas seres humanos podem contar suas histórias, já que os animais e as bestas são desprovidos de língua; desta maneira, a narrativa se torna uma forma de resistir à violenta desumanização exercida pelo poder colonial e de se reafirmar a humanidade que o poder colonial fez questão de negar e subtrair dos povos das colônias.

Algumas observações tornam-se importantes antes de prosseguirmos para a análise do romance de Acevedo no que diz respeito ao pós-colonial. Em seu artigo "A topologia do Ser e a geopolítica do conhecimento. Modernidade, império e colonialidade", Nelson MALDONADOTORRES (2008) aponta que, na maioria dos casos, os estudiosos do pós-colonial aceitaram a autodefinição da modernidade que fixou seu início temporal no período que vai do final do séc. XVIII ao início do séc. XIX. Desta forma, acabam perdendo de vista a importância central que a americanidade teve na modernidade. Maldonado-Torress não despreza a importância do colonialismo do séc. XIX, que trouxe consigo novas tecnologias no que diz respeito à subordinação e controle colonial; tecnologias essas que, de fato, reformularam a relação existente entre modernidade e experiência colonial. Entretanto, afirma ele, "a lógica que animou os processos imperiais não foi assim tão diferente dos padrões que surgiram no contexto da conquista das Américas" (MALDONADO-TORRES, 2008, p. 86). Evidenciar a importância da americanidade parecenos fundamental no processo de análise do romance escolhido, em primeiro lugar pelo motivo óbvio de ser situado no Caribe e, em segundo lugar, para apontarmos a ausência de ameríndios na narrativa, o que evidencia o processo de apagamento, ou melhor, a colonização da memória e das noções de si, apontadas por Lugones (2014a, p. 938).

O romance The Distant Marvels é situado em Cuba, no ano de 1963, durante a passagem do furacão Flora pela ilha. Durante alguns dias, sete senhoras são evacuadas de suas casas e ficam confinadas em uma das salas de uma residência governamental da época colonial. É nesse contexto que a protagonista/narradora, María Sirena, antiga lectora de uma fábrica de charutos, conta a história completa de sua vida, em especial de sua infância e adolescência durante a Guerra de Independência Cubana (1895-1898). Seus pais, Augustín e Lulu, lutam na guerra ao lado dos rebeldes, o que faz com que a família se desloque por vários lugares da ilha durante os tempos turbulentos. Anos depois de terminada a guerra, Sirena se casa e inicia sua família. Assim, logo de início, a narradora/protagonista começa a se revelar como uma representação literária do narrador descrito por Walter Benjamin, uma vez que ela tanto se desloca, durante sua infância e adolescência, quanto se estabelece e desenvolve sua arte de contar histórias. Ao final do romance, os leitores descobrem como a protagonista se tornara lectora na fábrica de charutos do homem com o qual se casou e como ela contava a história de sua vida para aqueles que a ouviam. Diz ela,

ele me fez leitora na fábrica charutos de seu pai, e foi ali onde contei aos trabalhadores partes da minha história, escrita por uma mulher chamada Carla Carvajal. Quando eles me perguntavam o nome do livro que eu estava lendo, eu respondia a eles que se chamava The Distant Marvels, e eles acreditavam em mim (ACEVEDO, 2015, p. 276). 
Sirena também é uma personagem que vive em um espaço não moderno, onde as ações da experiências (erfahrung) parecem continuar existindo e é dessas experiências que tira o material de suas histórias. Ademais, suas experiências relatadas são tanto aquelas pelas quais passou individualmente quanto as que ouviu de seus pais e pessoas com as quais conviveu durante a guerra. Um bom exemplo está logo no início do romance, quando a narradora Sirena chega à Casa Velázquez e declara: "eu sei como se parece lá dentro apesar de nunca ter cruzado a soleira da porta" (ACEVEDO, 2015, p. 37). Augustín, seu pai, havia morado nesta casa durante o período em que sua mãe, Inconsolada, trabalhara lá como governanta. Essas histórias eram contadas a ela pelo pai durante suas viagens no período da guerra. Outro exemplo também diz respeito ao pai da narradora, que era - ele mesmo - um grande narrador. Sirena relata: "tal como todo bom tirano, Augustín era um contador de histórias que se lembrava das coisas em grande detalhes, e aqueles dos quais não se lembrava, ele inventava. Pode ser que nada disso seja verdade. Mas me lembro com muita precisão, como se as tivesse vivido".' Aquilo que aprendeu com o pai, as histórias, a memória do narrador e sua habilidade de contar histórias, Sirena exercita conscientemente.

De acordo com Walter Benjamin (1987a), "a morte é a sanção de tudo o que o narrador pode contar. É da morte que ele deriva a sua autoridade" (p. 207). Como supramencionado, essa é mais uma característica importante a qual utilizamos neste artigo para localizar as características do narrador benjaminiano no romance The Distant Marvels. A protagonista de Chantel Acevedo é uma mulher idosa que foi forçadamente tirada de sua casa e levada com as demais mulheres para Casa Velázquez; ela recusa a oferta de seus vizinhos de deixar sua residência antes que o furacão chegue porque entende já ter vivido muito tempo. María Sirena é uma protagonista/ narradora que está pronta para morrer e se encontra em meio de uma calamidade natural, uma das maiores que sua ilha já enfrentou. Ela carrega em si a experiência de pessoas que já morreram, se tornando assim alguém com a autoridade esperada por Benjamin. Ademais, há na narradora a preocupação que Benjamin demonstra em seu texto "Experiência e pobreza" (1987b [1936]) e que serviu de epígrafe para este artigo. Para ilustrarmos essas características, apontamos uma declaração de Sirena, a narradora,: "as lágrimas pressionam minhas pálpebras cerradas. Minhas pernas e braços parecem estar algemados. As histórias pesam tanto. Quem as carregará quando me for? Beatríz? Eu mal conheço minha própria filha. Ela se mudou para Havana para se tornar uma estranha para sua mãe" (ênfase nossa). ${ }^{2}$

O peso das histórias que María Sirena sente em seu próprio corpo, como se suas pernas e braços estivessem presos em algemas, também nos parece um bom exemplo de como as histórias retiradas da experiência não se limitam à voz. Elas estão impressas "na alma, no olhar, nas mãos" (BENJAMIN, 1987a, p. 220); as histórias afetam seu corpo todo. Durante uma pausa, Sirena percebe que está tonta. Em suas palavras,

uma onda de vertigem me abate. Estou sonhando. Tenho certeza. Está acontecendo novamente, me perder em um sonho ou uma memória, como acontecera lá embaixo quando eu podia jurar que estava cercada pelos escravos do governador. Me sinto inclinando para a direita, como se estivesse em um barco em águas bravas (ACEVEDO, 2015, p. 73-74).

Essa última característica a ser apontada neste artigo é bastante importante, pois, de acordo com Benjamin, é ela que liga a arte da narrativa à sua própria matéria, que é a vida humana. O crítico alemão lança, então, um questionamento filosófico acerca do papel do narrador: "não seria sua tarefa trabalhar a matéria-prima da experiência - a sua e a dos outros - transformandoa num produto sólido, útil e único?" (BENJAMIN, 1987a, p. 221). Ao final do ensaio, Benjamin conclui que o poder do narrador é o de contar sua vida e contá-la inteira. Duas passagens do romance apontam para esse poder do narrador de contar sua vida, uma vida que se mistura a outras. A primeira está no início do romance, quando María Sirena começa a contar a história de sua vida para suas companheiras:

Essa história aconteceu logo depois da segunda guerra pela independência, eu digo. "Há um homem na história chamado Augustín, que era um herói e um monstro. E uma mulher, chamada Lulu, que amava Augustín às vezes, e o odiava outras vezes, e se amava ainda mais. Para mim eles eram mamãe e papai [...] (ACEVEDO, 2015, p. 59).

A outra está no final do romance, depois de revelar seus maiores segredos àquelas mulheres e já se encontrar em seu leito de morte. Todo o peso de sua experiência já fora transmitido e ela se sente leve, amada, perdoada. A narradora conclui:

[F]echo meus olhos e imagino o mar, calmo como um espelho. Me imagino boiando nele. Não há vento para agitar as águas. Há apenas a luz do sol. Há apenas uma história que tento contar

\footnotetext{
' No original: "Like a good tyrant, Augustín was a storyteller, so that he remembered things in great detail, and what he didn't remember, he made up. None of this may be true. But I recall it with precision, as if l'd lived it" (ACEVEDO, 2015, p. 50). ${ }^{2}$ No original: "Tears press against my closed eyelids. My legs and arms feel like they're manacled. The stories weigh so very much. Who will carry them when l'm gone? Beatríz? I hardly know my own daughter. She went off to Havana to become a stranger to her mother" (ACEVEDO, 2015, p. 96).
} 
para mim mesma para passar o tempo, sobre uma sereia, e uma menina, e sobre amor sendo construído em cima de amor através do curso de uma vida (ACEVEDO, 2015, p. 290).

Sobre a colonialidade e os povos originais, Aníbal QUIJANO e Immanuel WALLERSTEIN (1992), em seu texto "Americanity as a concept, or the Americas in the modern world-system", lembram do processo de extermínio dos povos indígenas e da importação da mão de obra ocorrida por todo continente americano de maneira sistemática, a tal ponto que não seria razoável se falar em reconstrução das instituições políticas e econômicas, mas de uma construção. Desta forma, eles acrescentam, "o modo de resistência cultural às condições opressivas esteve menos na busca por uma historicidade do que numa corrida rumo à 'modernidade'" (QUIJANO; WALLERSTEIN, 1992, p. 549). ${ }^{3}$ Acevedo, de fato, cai nessa armadilha e deixa de construir uma personagem que explicitamente representasse os povos originais. Entretanto, por toda sua narrativa, o romance apresenta questões próprias da colonialidade, como pode ser visto, por exemplo, no desprezo e na violência de Augustín, pai da protagonista, quando descobre que a filha tem um romance com um rapaz negro. O sistema de raça está posto no romance. Apesar de lutar pela independência de Cuba do mesmo lado que Augustín, Mario entende que há uma hierarquia que se baseia na cor da pele. Em uma conversa com María Sirena, depois de darem seu primeiro beijo, Mario se mostra apreensivo. A protagonista argumenta que o relacionamento não trará nenhum problema porque eles estão vivendo numa nova era, ao que ele responde:

São apenas palavras... Meu regimento é todo de pretos e em cada batalha somos colocados na vanguarda. Todas as vezes, María Sirena, estamos na linha de frente. Somos descartáveis. Os regimentos dos brancos aguardam até que a gente vença os espanhóis, e quando estamos cansados demais ou muitos de nós mortos, eles aparecem com seus machados em riste. Os grandes heróis brancos (ACEVEDO, 2015, p. 174). ${ }^{4}$

Outro aspecto da colonialidade - e da mesma forma, da descolonialidade - nos é apresentado por Maria Lugones, que busca conscientizar a realidade de que na colonialidade de gênero, apenas os civilizados, ou seja, o indivíduo europeu, burguês, cristão poderia ser homem ou mulher. Os demais, os colonizados, seriam não humanos e, portanto, passivos de sofrerem todo tipo de violência em seus corpos, memórias e afetos. Essa necessária interseccionalidade escapa mesmo às mulheres brancas. Em seu texto "Radical Multiculturalism and Women of Color Feminism (2014b), Lugones afirma, em relação às mulheres brancas, que

[...] elas não se percebem em termos interseccionais, na intersecção da raça, do gênero e de outras marcas violentas de sujeição ou dominação. Uma vez que elas não percebem essas diferenças profundas, elas não veem a necessidade de se criar coalizões. Presumem uma sororidade, um laço que se dá a partir da sujeição de gênero (p. 70). ${ }^{5}$

Acevedo parece apresentar essa ausência de uma consciência interseccional que várias mulheres feministas brancas carregam na relação que se estabelece entre María Sirena e a jornalista estadunidense Blythe Quinn, que vai a Cuba para investigar sobre os campos de concentração estabelecidos pelos espanhóis durante a guerra de independência. Apesar de ajudar a protagonista a escapar do campo e a ter seu filho em segurança, Blanca Lora, como a jornalista era conhecida em Cuba, ignora a condição de María Sirena enquanto uma cubana descendente de espanhol, porém mãe de um filho negro, e a convence a ir para Nova lorque. De certa forma, convencida de que estaria melhor nos Estados Unidos, Sirena entrega seu filho a desconhecidos que o levariam ao país com a promessa de que em breve se reuniria com ele. Depois de perceber que isso não aconteceria, a protagonista escreve cartas à jornalista e não obtém resposta, até décadas depois, quando recebe um envelope com um artigo de jornal traduzido para o espanhol, de autoria de Quinn, e que contava sua história e a de seu filho. Para o público estadunidense, Sirena não tem voz, ela é apenas uma personagem com um pseudônimo (Carla Carvajal). Ao final do artigo, Quinn declara, sem muita emoção: "ao mesmo tempo em que estou encantada com o final feliz que foi guardado para o menino, eu gostaria de ter visto Carla Carvajal novamente e de ter mostrado Nova Iorque a ela, como prometi mais de uma vez durante a guerra" (ACEVEDO, 2015, p. 274). ${ }^{6}$ Não há, da parte de Quinn, a jornalista estadunidense branca, nenhuma empatia verdadeira pela protagonista

\footnotetext{
${ }^{3}$ No original, "... from the beginning, the mode of cultural resistance to oppressive conditions was less in the claims of historicity than in the flight forward to 'modernity'" (QUIJANO; WALLERSTEIN, 1992, p. 549).

${ }^{4}$ No original, "That's all words... My regiment is all black and in each battle we're assigned to the vanguard. Even time, María Sirena, we're at front of the line. We're disposable. The white regiments wait for us to plow through the Spanish, and when we're sufficiently tired or enough of us are dead, they come in, machetes in the air. The great white heroes" (ACEVEDO, 2015, p. 174).

${ }^{5}$ No original, "... they did not understand themselves in interseccional terms, at the intersection of race, gender, and other forceful marks of subjection and domination. Because they did not perceive these deep differences they did not see a need for creating coalitions. They presumed a sisterhood, a bond given with the subjection of gender" (LUGONES, 2014a, p. 70).

${ }^{6}$ No original, "While I am delighted at the happy turn of events for the boys, I would have liked to see Carla Carvajal again, and to have shown her New York, as I had promised on more than one occasion during the war" (ACEVEDO, 2015, p. 274).
} 
que levasse em consideração sua condição de mulher racializada. Há apenas um lamento de não ter tido a oportunidade de levá-la para passear em Nova lorque. Ela ignora o que realmente aconteceu com Sirena na ocasião em que foi separada de seu filho e nada fez para descobrir a verdade. Desta forma, parece-nos que, ao trazer uma narradora/protagonista que conta não apenas sua história pessoal, mas também a história de um momento tão importante de sua nação - narradora essa que apresenta características consideradas importantes e raras para um intelectual da envergadura de Walter Benjamin, características essas que localizamos para fins deste artigo como não modernas -, Chantel Acevedo faz do romance The Distant Marvels um exercício de resistência, a resistência que se dá naquela "noção mínima de agenciamento para que a relação opressãoresistência seja uma relação ativa" (LUGONES, 2014a, p. 940) e que contribui para a construção de novas epistemologias, em especial no campo das intervenções feministas descoloniais.

\section{Referênclas}

ACEVEDO, Chantel. The Distant Marvels. New York: Europa Editions, 2015.

APARICIO, Juan Ricardo; BLASER, Mario. "The 'Lettered City' and the Insurrection of Subjugated Knowledges in Latin America". Anthropological Quarterly,v. 81, n. 1, p. 59-94, 2008. Disponível em: http://www.jstor.org/stable/30052740. Acesso em: 07/07/2017.

BENJAMIN, Walter. "O narrador. Considerações sobre a obra de Nikolai Leskov". In: BENJAMIN, Walter. Magia e técnica, arte e política: ensaios sobre literatura e história da cultura. São Paulo: Brasiliense, 1987a. p. 197-221.

BENJAMIN, Walter. "Experiência e pobreza". In: BENJAMIN, Walter. Magia e técnica, arte e política: ensaios sobre literatura e história da cultura. São Paulo: Brasiliense, 1987b [1936]. p. 114-119.

LUGONES, Maria. "Rumo a um feminismo descolonial". Revista Estudos Feministas, Florianópolis, v. 22, n. 3, p. 935-952, jan. 2014a. Disponível em https://periodicos.ufsc.br/index.php/ref/article/view/ 36755. Acesso em 07/07/2017. ISSN 1806-9584

LUGONES, Maria. "Radical Multiculturalism and Women of Color Feminisms". JCRT, v. 13, n. 1, 2014b.

MALDONADO-TORRES, Nelson. A topologia do Ser e a geopolítica do conhecimento. Modernidade, império e colonialidade. Revista Crítica de Ciências Sociais, v. 80, p. 71-1 14, 2008. Disponível em https://rccs.revues.org/695\#quotation. Acesso em 07/07/2017. DOI: 10.4000/rccs 695

QUIJANO, Aníbal; WALLERSTEIN, Immanuel. Americanity as a concept, or the Americas in the modern world-system, 1992. Disponível em https://www.javeriana.edu.co/blogs/syie/files/Quijano-andWallerstein-Americanity-as-a-Concept.pdf.

Priscilla da Silva Figueiredo (priscillafigueiredo.rj@gmail.com) é doutoranda em Literaturas de Língua Inglesa no Programa de Pós-Graduação em Letras da Universidade do Estado do Rio de Janeiro (PPGL-UERJ), bolsista CNPq e mestre em Letras - Literaturas de Língua Inglesa. Atua principalmente nos seguintes temas: Literatura e Estado de Exceção, Literatura contemporânea, Literaturas em língua inglesa, Novas diásporas e Decolonialidade.

\section{COMO CITAR ESSE ARTIGO DE ACORDO COM AS NORMAS DA REVISTA}

Como citar esse artigo de acordo com as normas da revista: FIGUEIREDO, Priscilla da Silva. "A narradora descolonial: uma leitura de 'The Distant Marvels', de Chantel Acevedo". Revista Estudos Feministas, Florianópolis, v. 27, n. 1, e59000, 2019.

\section{CONTRIBUIÇÃO DE AUTORIA}

Concepção, coleta e análise de dados, bem como elaboração do manuscrito e redação

FINANCIAMENTO

Capes, via bolsa de Doutorado

CONSENTIMENTO DE USO DE IMAGEM

Não se aplica 


\section{APROVAÇÃO DE COMITÊ DE ÉTICA EM PESQUISA}

Não se aplica

\section{CONFLITO DE INTERESSES}

Não se aplica

\section{LICENÇA DE USO}

Este artigo está licenciado sob a Licença Creative Commons CC-BY. Com essa licença você pode compartilhar, adaptar, criar para qualquer fim, desde que atribua a autoria da obra.

\section{HISTÓRICO}

Recebido em 03/09/2018

Aprovado em 07/09/2018 